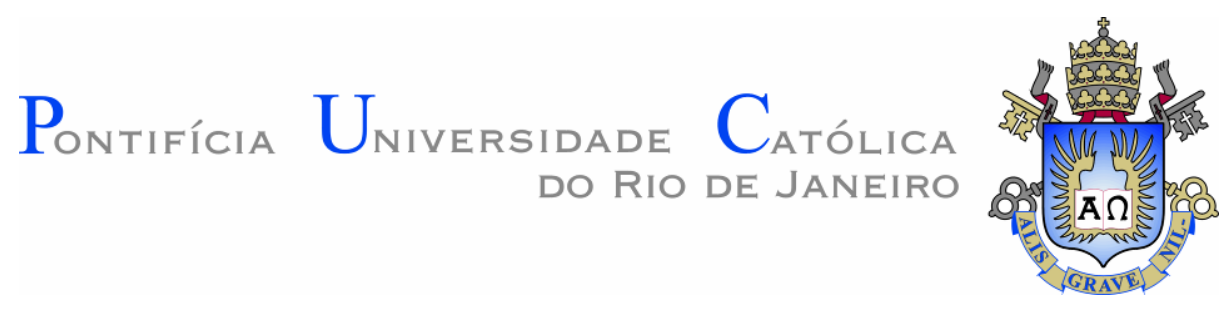

Amaury Garcia dos Santos Neto

\title{
Burgess por Dentro: Espaços (Auto)Biográficos
}

\section{Tese de Doutorado}

Tese apresentada como requisito parcial para obtenção do título de Doutor pelo Programa de PósGraduação em Literatura, Cultura e Contemporaneidade da PUC-Rio.

Orientador: Profa. Heidrun Friedel Krieger Olinto de Oliveira 


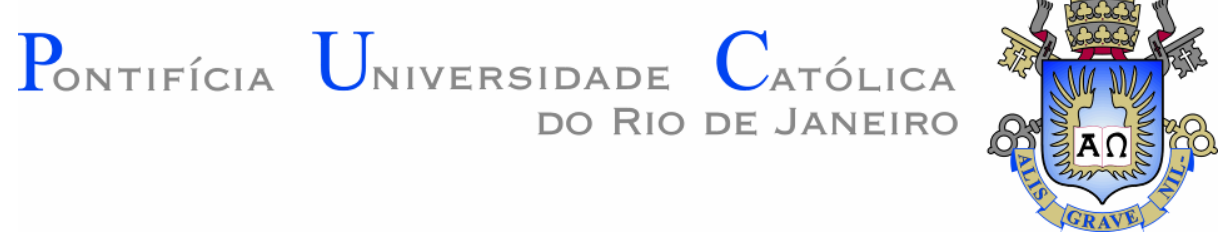

Amaury Garcia dos Santos Neto

\section{Burgess por Dentro: Espaços (Auto)Biográficos}

Tese apresentada como requisito parcial para obtenção do título de Doutor pelo Programa de Pós-Graduação em Literatura, Cultura e Contemporaneidade do Departamento de Letras do Centro de Teologia e Ciências Humanas da PUC-Rio. Aprovada pela Comissão Examinadora abaixo assinada.

Profa. Heidrun Friedel Krieger Olinto de Oliveira Orientadora Departamento de Letras - PUC-Rio

Profa. Daniela Gianna Claudia Beccaccia Versiani Departamento de Letras - PUC-Rio

Profa. Ana Lucia de Souza Henriques Instituto de Letras - UERJ

Prof. Anderson Soares Gomes Instituto de Ciências Humanas e Sociais - UFRRJ

Profa. Elisa Lima Abrantes Instituto de Ciências Humanas e Sociais - UFRRJ

Profa. Denise Berruezo Portinari Coordenadora Setorial do Centro de Teologia

e Ciências Humanas - PUC-Rio

Rio de Janeiro, 26 de março de 2015. 
Todos os direitos reservados. É proibida reprodução total ou parcial do trabalho sem autorização da universidade, do autor e da orientadora.

\section{Amaury Garcia dos Santos Neto}

Graduou-se em língua inglesa e respectivas literaturas pela UERJ em 2002. Obteve o título de Mestre em Literaturas de Língua Inglesa pela UERJ em 2005. Em sua dissertação, orientada pela professora doutora Ana Lúcia de Souza Henriques, tratou dos temas educação e livre arbítrio em romances distópicos de autores ingleses, mais especificamente nas obras Brave New World, de Aldous Huxley e A Clockwork Orange, de Anthony Burgess. Trabalhou como professor substituto de Literaturas Inglesa e Americana na UFRJ, nos anos de 2007 e 2008. Atualmente é professor de língua inglesa no Colégio Militar do Rio de Janeiro.

Ficha cartográfica

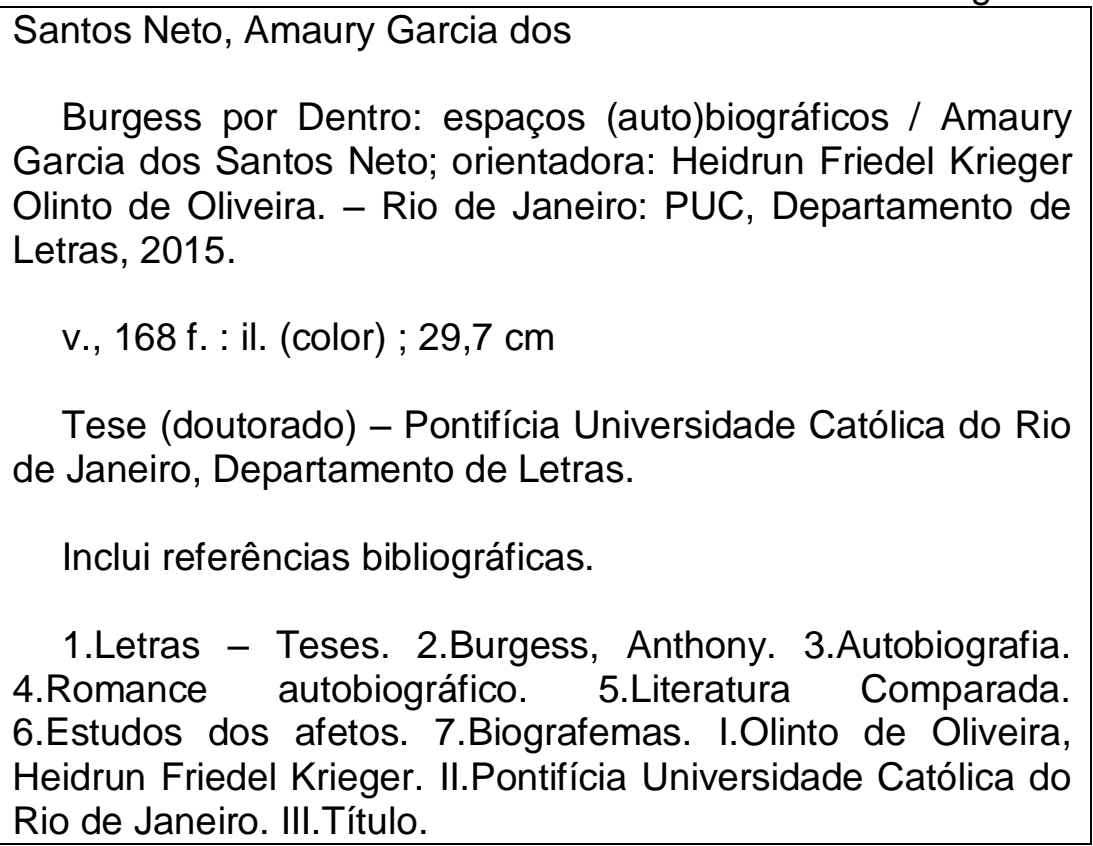


Dedico esta tese a meu amor, minha esposa, amiga, companheira, Juliene Kely Zanardi, única pessoa a quem mostro todos os fragmentos de subjetividade que formam este ser tão imperfeito que sou. 


\section{Agradecimentos}

À minha orientadora, professora Heidrun Friedel Krieger Olinto de Oliveira, por sua orientação, dedicação e paciência com o projeto que resultou nesta tese.

Ao Conselho Nacional de Desenvolvimento Científico e Tecnológico (CNPq) e à PUC-Rio, pelos auxílios concedidos, sem os quais este trabalho não poderia ter sido realizado.

Aos professores que participaram da Comissão examinadora, Ana Lúcia de Souza Henriques, Daniela Gianna Claudia Beccaccia Versiani, Elisa Lima Abrantes, Anderson Soares Gomes, por seus conselhos.

Aos professores Karl Erik Schøllhammer, Rosana Kohl Bines, Luiz Manoel da Silva Oliveira e Mariana Maia Simoni.

A Andrew Biswell, professor da Universidade Metropolitana de Manchester e diretor da International Anthony Burgess Foundation na cidade de Manchester, e a seu assistente, Will Carr, pela paciência e apoio.

Ao Board of Trustees da International Anthony Burgess Foundation, que me apoiou financeiramente durante minha pesquisa aos arquivos de Anthony Burgess.

Ao meu pai, Amaury Garcia dos Santos Filho, à minha mãe, Iára Vettori dos Santos, à minha irmã, Ivy Araçary Vettori dos Santos, e ao meu irmão, Renê Michel Vettori dos Santos, pelo apoio.

Aos colegas de pesquisa que me auxiliaram de diversas formas, enriquecendo minha tese, como Rogério Pacheco Jordão, Aline Moura, Mayumi Aibe, Shirley Lira e Simon Johnson.

Agradecimentos especiais à minha esposa, Juliene Kely Zanardi, por ter não apenas me apoiado, mas também participado da pesquisa, inventariando material na International Anthony Burgess Foundation, revisando meus textos, sugerindo o título de minha tese e, principalmente, me oferecendo o suporte emocional tão importante para tal tarefa.

Por último, agradeço a Anthony Burgess, cuja obra me tocou de tal maneira que não tive escolha a não ser buscar entendê-lo mais a fundo. 


\section{Resumo}

Santos Neto, Amaury Garcia dos; Oliveira, Heidrun Friedel Krieger Olinto de (Orientadora). Burgess por dentro: espaços (auto)biográficos. Rio de Janeiro, 2015. 168 p. Tese de Doutorado - Departamento de Letras, Pontifícia Universidade Católica do Rio de Janeiro.

Esta tese discute criticamente e questiona pressupostos teóricos que orientam a recepção de escritas de si como textos referenciais definidos pela tripla identificação entre autor, narrador e personagem. Em seu lugar, sugere-se um modelo que acentua o caráter construtivo de discursos (auto)biográficos, ambiguamente localizados entre fatos e ficções. Neste âmbito, propõe-se analisar comparativamente autobiografia e romance autobiográfico, a partir de conceitos tais como biografema e espaço biográfico. Tais conceitos possibilitam uma dinâmica relacional que proporciona construções (auto)biográficas alternativas que buscam dar conta da flexibilidade e complexidade inerente ao conceito de identidade como concebido no cenário contemporâneo. Baseado na hipótese de que textos referenciais recebem menor investimento afetivo por parte do leitor quando comparados a textos cujos processos de deciframento são mais complexos, como no caso de textos literários, evidencia-se a criação de um espaço relacional entre o primeiro tomo da autobiografia do romancista inglês Anthony Burgess, O pequeno Wilson e o grande Deus (1993), e um romance de sua autoria, Enderby por dentro (1990). A partir deste espaço, são abordados fragmentos autobiográficos recorrentes nos dois títulos que, por serem construídos por meio de estratégias distintas, provocam diferentes efeitos e afetos. Quando comparados, tais efeitos geram novas dimensões de compreensão acerca da complexidade da identidade da figura em foco. Neste sentido, a tese busca comprovar a hipótese de que na escrita (auto)biográfica, a própria motivação e finalidade documental referencial pode ser minimizada em favor da proposta estética, que tem o potencial de proporcionar maior complexidade à identidade (auto)biográfica.

\section{Palavras-chave}

Burgess, Anthony; Autobiografia; Romance autobiográfico; Estudos dos afetos; Biografema. 


\section{Abstract}

Santos Neto, Amaury Garcia dos; Oliveira, Heidrun Friedel Krieger Olinto de (Advisor). Inside Mr. Burgess: (auto)biographical spaces. Rio de Janeiro, 2015. 168 p. PhD Thesis - Departamento de Letras, Pontifícia Universidade Católica do Rio de Janeiro.

This thesis critically approaches and questions theoretical grounds that argue that so-called writings of the self are referential texts defined by the triple identification of author, narrator and character. Another model is suggested, one that stresses the constructive nature of (auto)biographical discourses which are ambiguously located between factuality and fictionality. In this regard, we propose to compare autobiography and autobiographical novel, using concepts such as biographeme and biographical space. These concepts can generate a relational dynamics that makes it possible to build alternative (auto)biographical constructions, which, in turn, can keep the flexibility and complexity inherent to the notion of identity in contemporary studies. Based on the hypothesis that referential texts are not as affectively received by the reader as texts whose deciphering processes are more complex - literary texts, for example -, we point to the creation of a relational space between the first volume of Anthony Burgess's autobiography, Little Wilson \& Big God, and his novel Inside Mr. Enderby. Considering such space, we approach autobiographical fragments of the said author that recur in both titles, which, as they are structured through different strategies, provoke different effects and affects. When compared, such effects generate new dimensions of understanding regarding the complexity of the identity of the figure which is focussed. Following this line of thought, the thesis tries to prove the hypothesis that in (auto)biographical writing referentiality can be minimised in the name of aesthetic purposes, since art would have the potentiality to confer more complexity to (auto)biographical identity.

\section{Keywords}

Burgess, Anthony; Autobiography; Autobiographical novel; Affect studies; Biographeme. 


\section{Sumário}

1. Introdução

2. Pressupostos teóricos 14

2.1. As escritas de si e o contexto contemporâneo 16

2.2. Autobiografia, romance autobiográfico e o espaço biográfico 23

2.3. Pressupostos construtivistas e a construção do self em 34 discursos autobiográficos

2.4. O espaço biográfico e o sistema literatura 47

2.5. A literatura e a questão dos afetos 63

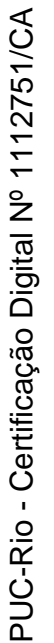

2.6. Autobiografias e ficções autobiográficas: interseções 73

3. Anthony Burgess e Enderby por dentro 80

3.1. Por que Anthony Burgess? 81

3.2. Francis Xavier Enderby: dejeto autobiográfico de Anthony Burgess 99

3.3. O pequeno Wilson e o grande Deus \& Enderby por dentro 110

4. Considerações finais 134

5. Mais que um simples anexo 137

6. Referências Bibliográficas 159 


\section{Lista de figuras}

Figura 1 - llustração feita por Anthony Burgess 96

Figura 2 - Edificação em que Anthony Burgess viveu 137

Figura 3 - Igreja do Santo Nome, situada em Manchester, Inglaterra 138

Figura 4 - Igreja do Santo Nome, situada em Manchester, Inglaterra 138

Figura 5 - Faculdade de artes da Universidade de Manchester $\quad 139$

Figura 6 - Placa comemorando Anthony Burgess 139

Figura 7 - Prédio da Faculdade de artes da Universidade de

Manchester. Ao fundo, topo da torre da Igreja do Santo Nome 139

Figura 8 - Entrada do Xaverian College, em Manchester, Inglaterra $\quad 140$

Figura 9 - Prédio de recepção do Xaverian College 140

Figura 10 - Prédio do Xaverian College $\quad 140$

Figura 11 - Corvo em árvore situada à entrada do Xaverian College $\quad 140$

Figura 12 - Modelos das mãos de Anthony Burgess 141

Figura 13 - Hapsichord que pertenceu a Anthony Burgess 142

Figura 14 - Máquina de escrever que pertenceu a Anthony Burgess 142

Figura 15 - Biblioteca pessoal de Anthony Burgess 143

Figura 16 - llustração em edição especial de Little Wilson \& Big God 143

Figura 17 - Certidão de óbito de Alexander George Mitchell 145

Figura 18 - Capa de texto em que Inside Mr. Enderby e Enderby

Outside foram adaptados para roteiro cinematográfico

Figura 19 - Capa de outro texto em que Inside Mr. Enderby e Enderby

Outside foram adaptados para roteiro cinematográfico 146

Figura 20 - Capa de edição de Inside Mr. Enderby 147

Figura 21 - Capa de edição de Inside Mr. Enderby 147

$\begin{array}{ll}\text { Figura } 22 \text { - Capa de edição de Enderby } & 147\end{array}$

Figura 23 - Capa de edição de The Complete Enderby 147

Figura 24 - Placa do pub The Neptune, situado em Brighton, Inglaterra 148

Figura 25 - Entrada do pub The Neptune 148

Figura 26 - Interior do pub The Neptune 148 
Bem sei que tudo na vida não passa de mentiras, e sei também que é nas memórias que os homens mentem mais. Quem escreve memórias arruma as coisas de jeito que o leitor fique fazendo uma alta idéia do escrevedor. Mas para isso ele não pode dizer a verdade, porque senão o leitor fica vendo que era um homem igual aos outros. Logo, tem de mentir com muita manha, para dar idéia de que está falando a verdade pura.

Monteiro Lobato, Memórias da Emília 